\title{
A FORMAÇÃO DE UM VÍNCULO AFETIVO ENTRE EDUCADORAS E CRIANÇAS COMO POSSIBILIDADE PARA UMA ADAPTAÇÃO FELIZ A CRECHE
}

\author{
Suélen Cristiane Marcos, Gilza Maria ZauhyGarms
}

Universidade Estadual Paulista - UNESP, Programa de Pós Graduação em Educação, Presidente Prudente, SP. E-mail: ssucris@hotmail.com. CAPES.

\begin{abstract}
RESUMO
Este trabalho é fruto de um recorte de uma pesquisa de doutorado em andamento, e tem por objetivo identificar as estratégias de promoção da adaptação infantil à creche utilizadas pelos profissionais da Educação Infantil. A pesquisa enquadra-se na modalidade tipo estudo de caso, numa abordagem qualitativa, envolvendo discussões sobre a inserção das crianças a creche, e o estabelecimento da parceria entre as famílias e as instituições de Educação Infantil para o sucesso da adaptação das crianças pequenas e para a qualidade da Educação Infantil. O campo de investigação foi uma instituição, pública de Presidente Prudente, que atende 182 crianças de 4,5 meses a 3 anos. Os procedimentos de coleta de dados foram entrevistas semi-estruturadas dirigidas às 11 educadoras e 7 professoras. Os resultados elucidam que os profissionais apontam como imprescindível para o sucesso da adaptação infantil a creche a formação de um vínculo afetivo entre educadoras, professoras e a criança.
\end{abstract}

Palavras-chave: (adaptação, creche, prática docente, crianças, afetividade).

\section{THE FORMATION OF A RELATIONSHIP BETWEEN AFFECTIVE EDUCATIONALISTS AND CHILDRENAS POSSIBLITY FOR ADAPTATION HAPPY NURSERY .}

\begin{abstract}
This work is the result of a cut of a doctoral research in progress, and aims to identify strategies to promote children's adaptation to day care used by professionals of early childhood education. The research is part of the mode type case study, a qualitative approach, involving discussions on the inclusion of children to day care, and the establishment of partnership between families and Early Childhood Education institutions for the successful adaptation of small children and the quality of early childhood education. The research field is an institution, public PresidentePrudente, which serves 182 children from 4.5 months to 3 years. The data collection procedures were semi-structured interviews addressed to 11 educators and 7 teachers. Results clarify that professionals point as essential to the success of children's adaptation to day care the formation of an emotional bond between educators, teachers and children.
\end{abstract}

Keywords: (adaptation, nursery, teaching practice, children, affectivity).

\section{INTRODUÇÃO}

Este trabalho é um recorte de uma pesquisa de doutorado em andamento que surge da necessidade de discutir o processo de adaptação das crianças de 4,5 meses a 3 anos na instituição creche, a partir das perspectivas dos profissionais e das famílias, na intenção de delinear possíveis caminhos na construção de uma parceria entre a família e a instituição de Educação Infantil.

No que se refere, especificamente, as concepções dos profissionais sobre o ingresso da criança a creche, temos a pretensão de averiguar as expectativas, como e por quais estratégias se valem as educadoras e professoras ao vivenciarem essa experiência. "Ouvir", ou seja, "dar voz," as educadoras elucidará como é o processo utilizado neste período de adaptação das crianças a instituição. Na concepção de Rapoport (2005, p. 19), a boa ação pedagógica, sensível às necessidades das crianças é imprescindível para a adaptação das mesmas, principalmente no caso dos bebês: 
A ação pedagógica das educadoras pode ser considerada um dos fatores mais relevantes em termos da adaptação dos bebês à creche. A qualidade dos cuidados depende em grande parte da habilidade de as profissionais prestarem atenção em cada um e levarem em conta as reações individuais dos bebês.

Partimos do pressuposto de que o processo de adaptação das crianças é um elo entre as instituições de Educação Infantil e as famílias, sendo necessário que cada uma dessas instituições entenda a importância de sua atuação. Sem a parceria entre as instituições de Educação Infantil e as famílias a adaptação das crianças, muitas vezes, tem se caracterizado por um processo angustiante para todos os envolvidos. São comuns situações de separação abrupta das crianças de suas famílias em que as crianças são conduzidas chorando para dentro das instituições de Educação Infantil pelos profissionais enquanto as famílias observam atônitas e impotentes.

O processo de adaptação das crianças nas instituições de Educação Infantil pode ser muito doloroso não só para a criança como para seus familiares, principalmente para a mãe, educada socialmente para cuidar de seu filho e que tem um vínculo muito forte com a criança, pois implica na separação da criança de seus familiares mesmo que apenas por um período do dia, todavia, enquanto os pais trabalham ou desempenham outras funções sociais é preciso escolher sob a cargo de quem ficará a educação das crianças. Tendo sido a decisão tomada é preciso lidar com a adaptação da criança e da família a essa nova realidade.

[...] esses cuidados podem se dar em creches e préescolas, em creches familiares ou lares vicinais; por um parente ou na casa da criança dispensados por uma babá/ empregada. Em qualquer um desses casos, a criança passa por um processo de adaptação até que esteja vivenciando a nova situação da forma que revele menor sofrimento pelo afastamento materno. (RAPOPORT, 2005, p. 9)

De acordo com Perissé (2007) a perca psicológica se traduz por um momento de fragilidade emocional que tende a acarretar a potencialização de inseguranças e angústias. Em concordância Balaban (1988, p. 25), aponta que a experiência da separação acontece em todas as fases da vida dos seres humanos e os afeta.

A separação afeta as crianças. Afeta os pais. Faz brotar sentimentos nos professores. O início da vida escolar pode ser uma ocasião excitante ou também uma ocasião agradável. Junto com aqueles que realmente estão encantados por estarem iniciando sua vida escolar, existem frequentemente outras crianças chorando ou pais tensos e nervosos. (BALABAN, 1988, p. 24).

A adaptação das crianças as instituições de Educação Infantil é um processo complexo, pois, de acordo com Rossetti-Ferreira e Vitória (1993), exige muito emocionalmente da criança. A criança tem que lidar com um novo ambiente, com a separação diária da mãe e dos familiares e com as novas pessoas que não pertencem a sua família, com o estresse da despedida da família na entrada, com a nova rotina da instituição, com a troca de fraldas, a hora de dormir, de se alimentar, com os novos relacionamentos com os educadores infantis e com outras crianças. A criança, geralmente, manifesta seus sentimentos relacionados a adaptação a instituição pelo choro que é a reação mais temida pelas famílias, lhes causando enorme desconforto. Rossetti-Ferreira e Vitória (2000) afirmam que o choro da criança é o fator que mais desencadeia a ansiedade dos pais.

Segundo Santos (2012, p.34), o choro é muito comum no período de adaptação das crianças que o manifestam principalmente na entrada e quando os pais, ou familiares vêm buscá-las.

O choro transmite o que os pequenos não sabem dizer. É preciso aprender a identificar a mensagem. 
Outro dado é o de que existem manifestações, como gritos, reações de mau humor, bater nas pessoas, deitar-se no chão, reações de passividade, de apatia, de resistência à alimentação ou ao sono, e comportamentos agressivos. A ocorrência de doenças também é bastante frequente. $O$ bebê pode somatizar seus sentimentos em relação à separação, apresentando sintomas físicos, como febre, vômitos, diarréia, bronquite, alergias, etc. Esses sintomas devem alertar para possíveis problemas de adaptação, mesmo que o bebê não chore na escola. (SANTOS, 2012, p.34).

Para Rizzo (2000), esses sintomas de saúde são passíveis de ocorrer porque o grande investimento emocional do bebê durante a adaptação pode torná-lo menos resistente a infecção.

O choro é constante em todas as fases da adaptação, pois através do choro as crianças muitas vezes conseguem manipular o responsável que está fazendo sua adaptação, também há casos em que forçam vômitos, recusam-se a alimentar-se, percebem que assim vão ter por perto aquela pessoa da qual não querem se separar.

O processo de adaptação na história da Educação Infantil, na maioria das vezes, é entendido pelos profissionais como sendo um período de tempo e espaço determinados pela instituição tendo como principal objetivo estimular as crianças a pararem de chorar. Ao acreditar que o sucesso da adaptação das crianças se traduz apenas na ausência de choro é desconsiderar toda uma situação emocional complexa que não se expressa apenas por ele e impedir muitas crianças e famílias de se adaptarem.

Considerando a complexidade do processo de adaptação o objetivo deste estudo foi identificar quais são as práticas docentes defendidas pelos profissionais para promover à adaptação infantil a creche, incentivando-nos, a partir dessas estratégias pensarmos se necessário, em possibilidades que torne o ingresso a creche uma experiência feliz para as crianças, minimizando o seu sofrimento e impedindo o desencadeamento de angústias.

\section{METODOLOGIA}

A pesquisa, foi aprovada pelo comitê de ética e pesquisa da FCT-UNESP, como consta o protocolo CAAE 52850316.7.0000.5402 é de natureza qualitativa, pois permite, ao pesquisador, o contato direto e prolongado com a situação a ser investigada, assim como a possibilidade de uma discussão abrangente dos dados coletados no campo de configuração do estudo.De acordo com Richardson (1999, p.39) a pesquisa qualitativa é uma metodologia que emprega estudos que podem descrever a complexidade de determinado problema, analisar a interação de certas variáveis, compreender processos dinâmicos sociais.

Esta pesquisa por ter como foco uma instituição de Educação Infantil de uma cidade do interior do Estado de São Paulo (SP), que atende 182 crianças, de 4,5 meses a 3 anos e como sujeitos os profissionais que atuam na instituição, 7 professores, 11 educadores e 30 famílias usuárias, cujos filhos passam pelo processo de adaptação as creches, a pesquisa enquadra-se na modalidade tipo estudo de caso.

A técnica empregada para recolha de dados foram entrevistas semi-estruturadas, dirigidas aos educadores, professores e as famílias para que explicitem suas expectativas sobre o processo de adaptação das crianças, tendo como meta delinear possíveis caminhos na construção de parcerias, se for o caso, num momento tão crucial, tanto para as famílias quanto para as educadoras e, sobretudo, para as meninas e meninos pequenos ao adentrarem o espaço da creche pela primeira vez.

Neste trabalho especificamente buscamos identificar e discutir quais são práticas de adaptação das crianças realizadas pela instituição de Educação Infantil, para isso nos focaremos na análise parcial das repostas oferecidas pelas 8 educadoras pertencentes a instituição participante.

As educadoras são responsáveis pelos níveis de berçário $\mathrm{I}$, que atende crianças de aproximadamente 3-4 a 10 meses e berçário II, que atende crianças de 10 meses a 2 anos. No berçário I cada educador cuida de seis bebês, no berçário II esse número sobre para oito bebês. As crianças do maternal I e II do período parcial têm 
como responsáveis apenas professoras e no período integral há alternância da professora com a educadora, as turmas do maternal são compostas por 16 crianças, de 2 a 3 anos.

Em respeito às normas éticas da pesquisa nomeamos as educadoras utilizando uma seqüência numérica, por exemplo: educadora 1 , educadora $2 . .$.

\section{RESULTADOS}

De acordo com Amorim; Vitória; RossettiFerreira, (2000) é no cenário creche que ocorre o desenvolvimento do campo \{Educadora-Criança\}, e o ambiente onde acontecem as atividades juntos com as crianças. No caso de bebês esse ambiente é o berçário, com berços, ou colchões, que possibilitam maior autonomia e desenvolvimento neuromotor, onde os bebês ficam grande parte do seu dia. É no ambiente creche que se dá a construção do vínculo entre criança e educadora, que por sua vez depende do relacionamento com as famílias, a direção da instituição e os objetivos educacionais. É desse momento de construção do vínculo entre criança e educadora ou professora que discutimos nesse artigo.

Ao ser indagada sobre que práticas, procedimentos, que utiliza para promover a adaptação das crianças a educadora 2 respondeu defendendo a ludicidade como meio de interação com as crianças, porém destaca a afetividade, paciência, carinho como imprescindível para auxiliar na adaptação infantil, já que a criança teme que a mãe não venha buscá-la, a tenha abandonado, não havendo atividades específicas para isso:

Eu acho que a afetividade é tudo, tem que ter muita paciência com a criança nesse momento, de explicar para a criança que a mãe vai, mas a mãe volta, porque a criança ás vezes tem a sensação que a mãe não volta buscar, elas têm a sensação que a mãe deixou elas aqui, tem que ter bastante conversa, paciência e carinho. (EDUCADORA 2).

$\mathrm{Na}$ adaptação a gente não dá muitas atividades específicas, tem que estar conversando, pegando no colo, a gente faz rodinha pra eles fazerem a apresentação deles, contarem a sua história, quem é o pai, quem é a mãe, a família, então é mais atividades da conversa mesmo, ai conforme eles vão se adaptando a gente vai fazendo as atividades. (EDUCADORA 2).

$\mathrm{Na}$ mesma linha de pensamento da educadora 2 , a educadora 6 , descreve sua prática como tendo como prioridade levar a criança a confiar nela, por meio da afetividade "Ó a gente primeiro tenta fazer a criança se acostumar com a gente e confiar na gente, é dando carinho, amor, brincar com ela, fazer elas se adaptarem com a gente". (EDUCADORA 6).

A educadora 3 afirma ser necessário para adaptar as crianças um ambiente agradável e o acolhimento das crianças por parte das educadoras para promover nas crianças a sensação de segurança.

Esse ambiente tem que ser bem agradável, ele não conhece o professor, essa nova pessoa que pra ele é novidade, então a gente precisa acolher bem a criança pra ela se sentir segura [...]. A gente sempre costuma assim trabalhar com eles com brinquedos, com coisas diferentes, fantoches, livros, bexigas, essas coisas assim, uns brinquedos diferentes, levar em outros ambientes da escola, colocar um desenho, um filme. (EDUCADORA 3).

Reda; Ujiie, (2009, p.10085) concordam com a educadora 3 ao defender a apresentação para as crianças de um ambiente prazeroso, seguro que Ihes possibilite ganhar a confiança da criança:

A função da instituição de Educação Infantil e dos profissionais é de receber a criança e acolher sua singularidade, enfim, apresentar-se como um ambiente seguro e estimulante. 0 professor 
deve ser 0 mediador principal no contexto da adaptação escolar, não deixando a sala de aula cair na rotina ao mesmo tempo em que ganha à confiança das crianças e familiares. A adaptação é um processo continuo de mudança, crescimento, desenvolvimento e amadurecimento para todos.

A educadora 4 compactua com a educadora 3 no sentido de que as práticas por elas adotadas no período de adaptação têm como objetivo primordial passar segurança para a criança e afirma que conquista as crianças com doces, mimos e atividades prazerosas, em suas palavras:

A gente chega com bala, a gente já conquista a criança com algum doce molinho porque é berçário 1 então é só no colo, ai você vem com bexigas, vem com algo pronto, mas o mais importante mesmo é ele sentir segurança, se você passar segurança, mesmo sem bala, sem bexiga, se ela gostar de você, se você conquistar ela assim, já é $80 \%$ da cura da adaptação, assim do choro, mas são esses procedimentos, trazer confiança, afetividade, as bexigas, as balas, as musiquinhas que a gente canta direito com eles, ficar no chão com eles, pra dar aquele envolvimento, aquela amizade, uma coisa mais próxima. (EDUCADORA 4).

Para Redá e Ujiie, (2009) conseguir se aproximar das crianças não é fácil é preciso possuir um olhar perspicaz para descobrir que ações permitem isso, como faz a educadora 4 ao trazer e proporcionar para as crianças o que elas gostam.

Criar um clima propício para a aproximação não é tão simples. É preciso um olhar cuidadoso e atento para perceber o que aproxima as crianças. Esse tipo de ação contribui para a consolidação de vínculos afetivos e de vivência. Nesses casos, o que está em jogo é o exercício da convivência, são as pequenas ações que fazem prevalecer à comunhão de uns com os outros, a socialização, enfim a efetivação do processo de adaptação de sucesso. (REDA; UJIIE, 2009, p.10087)

A educadora 8 e 11 defendem a necessidade de pegar os bebês no colo quando estão em adaptação a creche: "[...] e dar muito carinho porque no começo eles não aceitam muita coisa, tem que dar muito colo, muito carinho, muito colo, é isso". (EDUCADORA 11).

Ai a gente sempre assim pega no colo, acalenta o que está mais desesperado, põe o chão e pega o outro, são muitas crianças pra gente.

As crianças se apegam mais a uma pessoa, eles criam referências. No começo eles aceitam qualquer pessoa que tira eles dessa agonia, do choro pegando eles no colo, levando pra fora. (EDUCADORA 8).

O que é corroborado pelas educadoras 9 e 10que destacam a importância de dar colo, carinho, atenção, principalmente, para as crianças que estão apresentando maiores dificuldades de adaptação.

Bom por mim, o que eu estou fazendo aquela criança que está com mais dificuldade eu tenho deixar mais no colo, tento deixar as crianças mais fáceis no chão, e a criança que tá com mais dificuldade procuro dar mais carinho, mais atenção pra ela.Tudo que eu for fazer com as outras, dar alimentação, dar banho, trocar, eu costumo 
fazer um pouco mais pra ela que está com dificuldades. (EDUCADORA 9).

Num primeiro momento a afetividade, tá sempre acalentando os que a gente pode porque são vários né, não tem como colocar todos nos braços, nós vamos fazendo esse processo de acordo com os necessitados, que estão chorando mais, dessa forma ai... (EDUCADORA 10).

O dar colo e atenção às crianças no momento difícil para elas que é a adaptação, quando estão chorando está de acordo com as orientações do Referencial Curricular Nacional para a Educação Infantil:

O choro da criança, durante - processo de inserção, parece ser o fator que mais provoca ansiedade tanto nos pais quanto nos professores. Mas parece haver, também, uma crença de que o choro é inevitável e que a criança acabará se acostumando, vencida pelo esgotamento físico ou emocional, parando de chorar.

[...] Deve ser dada uma atenção especial às crianças, nesses momentos de choro, pegando no colo ou sugerindo-lhes atividades interessantes (BRASIL. Ministério da Educação e do Desporto, 1998, p. 79).

As educadoras demonstram estarem atentas as necessidades e preferências das crianças no seu cotidiano, o que fica evidenciado por meio de suas falas acima $O$ que está de acordo com o documento orientador da Unesco que afirma que o saber ouvir criança por parte da profissional que a atende é um aspecto importantíssimo ao acolhimento das crianças de qualquer idade:

Ao perceber que é acolhida e valorizada em vários aspectos do seu desenvolvimento, criança interage com 0 novo contexto mais facilmente, e ela reconhece nesse ambiente um espaço onde é aceita, com suas limitações e anseios, por pessoas atentas a cada descoberta que realizar. (BRASIL, 2011, p.17)

\section{DISCUSSÃO}

É evidente que as profissionais consideram importante no momento de adaptação das crianças acolherem as mesmas, oferecer carinho e atenção, na tentativa de conquistarem a simpatia da criança, passaremIhes, confiança e segurança. Nós compactuamos com a dimensão afetiva na prática das educadoras, o se importar com a criança é louvável, pois, segundo Diesel (2003) é a relação afetiva com o outro que possibilita a necessária segurança para explorar o novo ambiente, todavia, as colocações carecem de um significado específico, de um trabalho sistematizado, coletivo, para a prática educativa. Neste sentido Oliveira (1995, p.127) orienta "acolher adequadamente a criança exige que se tenha um trabalho coletivo, em que todos se empenhem em organizar o espaço e a estrutura da escola, visando atender as necessidades infantis".

Acreditamos que as educadoras e professoras participam do processo de adaptação infantil, envolvem-se com ele, são afetadas pelas emoções infantis que exemplifico com a descrição da EDUCADORA 1"voltar a ser criança”. O que está de acordo com as concepções de Reda; Ujiie (2009, p.10087) "Participar do processo de adaptação é estar implicado nele, é contagiar-se com a emoção que a interação com a criança proporciona", todavia, as profissionais tiveram dificuldades ao definirem a sua prática em considerarem como se estabelece a dinâmica entre a turma, em esclarecerem como organizam a rotina das crianças, as atividades que desenvolvem, incluindo como se dá as continuidades das atividades lúdicas por elas citadas e o relacionamento com as famílias, acreditamos que todos esses elementos devem ser considerados para se garantir o sucesso da adaptação.

\section{CONCLUSÃO}

Chama a atenção nas informações fornecidas pelas educadoras que, embora, as 
práticas de adaptação sejam em sua maioria exitôsas não existe uma proposta pedagógica, coletiva ou individual, visando à adaptação das crianças, a não ser o prazo de uma semana, para que a permanência da criança a creche vá sendo aumentada gradualmente, estipulado pela Secretaria Municipal de Educação, como exemplifica a fala "não havendo atividades específicas para isso" (EDUCADORA 1). Acreditamos que a afetividade é uma estratégia eficiente para se adaptar as crianças, todavia, para adaptar a criança de forma significativa é preciso uma prática fundamentada teoricamente, cientificamente, que possibilite estabelecer um planejamento, que inclua atividades de acolhimento à criança e a sua família, a organização dos espaços, a capacidade de se relacionar com as famílias, ganhar a confiança das mesmas e estabelecer uma parceria com elas no processo de adaptação, são fatores que afetam positivamente a criança. Fazem-se prementes investimentos na formação continuada dos docentes para que amplie qualitativamente as práticas de adaptação das crianças a creche.

\section{REFERÊNCIAS}

AMORIM, K. DE S; VITÓRIA, T; ROSSETTIFERREIRA, $M$, C. Rede de significações: perspectiva para análise da inserção de bebês na creche. Cadernos de Pesquisa, n. 109, p. 115144, mar./2000.

BALABAN, Nancy. 0 início da vida escolar: da separação à independência. Porto Alegre: Artes Médicas, 1988.

BRASIL. Série mesa educadora para a primeira infância. Brasília: MEC/UNESCO, 2011. v.3, p. 194.

BRASIL. Ministério da Educação e do Desporto. Secretaria de Educação Fundamental. Referencial curricular nacional para a educação infantil. Brasília: MEC/SEF, 1998. v.1

DIESEL, M. Adaptação escolar: sentimentos e percepções do educador diante da questão. Revista do Professor, Porto Alegre, n.19, p. 1013, abr/jun. 2003.

OLIVEIRA, Zilma M. Ramos de. A criança e seu desenvolvimento perspectivos para se discutir a educação infantil. São Paulo: Cortez, 1995.

PERISSÉ, P.M. Os desafios da adaptação. Pátio Educação Infantil, Porto Alegre, n.13, p.41-43, mar/jun. 2007.
RAPOPORT, Andrea. Adaptação de bebês à creche: a importância da atenção de pais e educadores. Porto Alegre: Mediação, 2005.

REDA, M. G.; UJIIE, N. T. A educação infantil e o processo de adaptação: as concepções de educadoras da infância. Disponível em: http://.www.pucpr.br/eventos/educere/educere 2009/anais/pdf/2496_1090.pdf. Acesso em: jan. 2015

RICHARDSON, Roberto J. et al. Pesquisa social: métodos e técnicas. São Paulo: Atlas, 1999.

RIZZO, Gilda. Creche: organização, currículo, montagem e funcionamento. 3. ed. Rio de Janeiro: Bertrand Brasil, 2000.

ROSSETTI-FERREIRA, Clotilde; VITÓRIA, Telma. Processo de Adaptação na creche. Cadernos de Pesquisa. São Paulo, n. 86, p.55-64, ago. 1993.

ROSSETTI-FERREIRA, Clotilde; VITÓRIA, Telma. Os fazeres na educação infantil. 2.ed. São Paulo: Cortez, 2000.

SANTOS, E. P. Adaptação da criança na educação infantil. Revista e-ped., Rio de janeiro, v. 2, n. 10, ago. 2012.

Recebido para publicação em 19/08/2016

Revisado em 26/08/2016

Aceito em 30/08/2016 